\title{
Adsorption, temperature and corrosion inhibition studies of a coumarin derivatives corrosion inhibitor for mild steel in acidic medium: gravimetric and theoretical investigations
}

\section{D.S. Zinad, ${ }^{1}$ Q.A. Jawad, ${ }^{2}$ M.A.M. Hussain, ${ }^{3}$ A. Mahal, ${ }^{4,5}$ L. Mohamed ${ }^{6}$ and A.A. Al-Amiery ${ }^{6} *$}

${ }^{1}$ Applied Science Department, University of Technology, Baghdad 10001, Iraq

${ }^{2}$ Electrical Department, University of Technology, Baghdad 10001, Iraq

${ }^{3}$ Al Rafidain University College, Department of Air-Conditioning and Refrigeration

Engineering Technology, Baghdad, Iraq

${ }^{4}$ Key Laboratory of Plant Resources Conservation and Sustainable Utilization and Guangdong Provincial Key Laboratory of Applied Botany, South China Botanical Garden, Chinese Academy of Sciences, Guangzhou 510650, People's Republic of China ${ }^{5}$ Guangzhou HC Pharmaceutical Co., Ltd, Guangzhou 510663, People's Republic of China ${ }^{6}$ Energy and Renewable Energies Technology Center, University of Technology, Baghdad 10001, Iraq

*E-mail: dr.ahmed1975@gmail.com

\begin{abstract}
The corrosion inhibition features of a new eco-friendly coumarin derivative, namely, 4-((4((4-hydroxy-3-methoxybenzylidene)amino)-5-thioxo-4,5-dihydro-1H-1,2,4-triazol-3-yl)methyl)coumarin (HATC), for corrosion of the mild steel surface in an acidic environment was studied using gravimetric techniques and quantum chemical calculations. It was concluded that the tested coumarin derivative is an excellent corrosion inhibitor with high inhibition efficiency. The inhibition performance increases with increasing concentration of the investigated coumarin (HATC) and decreases with increasing temperature. The mechanism of adsorption includes a physical adsorption mechanism. Theoretical studies done on the new coumarin molecule using the density functional theory (DFT) have shown that the most likely entities in coumarin molecules to bond to the metal surface are nitrogen, sulfur and oxygen atoms.
\end{abstract}

Keywords: corrosion inhibition, HATC, coumarin, quantum chemical calculation, adsorption.

Received: December 1, 2019. Published: January 31, 2020

doi: $\underline{10.17675 / 2305-6894-2020-9-1-8}$

\section{Introduction}

Mild steel is one of the most important engineering alloys because it has significant mechanical characteristics, which made it widespread in addition to cheapness and strength. Corrosion intensity increases when a mild steel surface is exposed to external conditions in 
an acidic environment [1]. Corrosion inhibitors are generally used in acid environments and therefore inhibitors are used to combat corrosion $[2,3]$. The process of selecting an appropriate corrosion inhibitor is one of the most important issues to consider when working in an acid environment, and therefore the use of organic compounds is of great importance [4-8]. The efficiency of organic compounds in corrosive solutions is attributed to several factors, the most important of which are the presence of functional groups and electron pairs in the phosphorus, sulfur, oxygen and nitrogen atoms, in addition to the double and triple bonds, as well as aromatic rings. Small amounts of corrosion inhibitors have the ability to block the corrosion sites and improve the adsorption process on the mild steel surface, thus protecting the mild steel surface and increasing its life time $[9,10]$. Previous studies demonstrate the possibility of employing organic molecules as anti-corrosion agents for mild steel in corrosive environment that were utilized for years. The literature shows that the inhibition of corrosion of a metal surface induces a mechanism of anti-corrosion adsorption on the metal surface and the inhibition efficiency depends in particular on the chemical composition of the corrosion inhibitor molecule and its chemical properties under certain experimental conditions. A large number of synthesized and natural organic compounds whose chemical structures contained nitrogen, oxygen and/or sulfur have been used as corrosion inhibitors in order to reduce the corrosion of steel in an acidic environment $[11,12]$. The electronic frontier is often used as an index of relative reactivity or stability of inhibitor molecule [13-16]. In light of previous studies [17-42], the present study reports the synthesis and characterization of a new eco-friendly coumarin compound, namely 4-((4-)(4hydroxy-3-methoxybenzylidene)amino)-5-thioxo-4,5-dihydro-1 $\mathrm{H}$-1,2,4-triazol-3-yl)methyl)coumarin (HATC), as well as a study of its behavior as a corrosion inhibitor and adsorption mechanism on the surface of mild steel in 1.0 molar hydrochloric acid using weight loss technique and a surface study technique. The effect of temperature on the dissolution of mild steel in acidic environment was studied in presence of HATC. The mechanism of inhibition was imputed based on density functional theory (DFT) calculations.

\section{Experimental}

\subsection{Chemistry}

Chemicals and solvents were purchased from Sigma-Aldrich, Kuala Lumpur, Malaysia. Chemicals were used without further purification. Spectroscopic techniques were used to characterize the chemical formula of HATC as a synthesized corrosion inhibitor. Fourier Transform Infrared (FT-IR) spectroscopy was used to record the spectrum of HATC for the purpose of identifying and characterizing the functional groups present in HATC. FT-IR spectra were recorded using a Nicolate 6700 Scientific Thermal Spectrophotometer for analysis. A preliminary analyzer Carlo Erba 5500 was used to determine the percentages of carbon, hydrogen and nitrogen in the HATC molecule. Nuclear magnetic resonance (NMR) spectra were recorded using AVANCE III $600 \mathrm{MHz}$. 


\subsection{Synthesis of corrosion inhibitor}

A mixture of equimolar quantities of 4-coumarinacetic acid (0.03 mole) and 4-aminothiosemicarbazide $(0.03$ mole $)$ was stirred and allowed to cool $\left(0-5^{\circ} \mathrm{C}\right)$ and phosphorus oxychloride $(15 \mathrm{~g})$ was then added. The mixture was then refluxed under reduced pressure to remove excess phosphorus oxychloride. Dry pyridine $(5 \mathrm{ml})$ was added. The mixture was poured onto ice. The precipitate was filtered off and recrystallized from ethanol. The yield of brown powder was $57 \%$. Melting point: $258^{\circ} \mathrm{C}$. The chemical structure is demonstrated in Scheme 1. 4-((4-Amino-5-thioxo-4,5-dihydro-1H-1,2,4-triazol-3-yl)methyl)coumarin (ATMC) was characterized by spectroscopic techniques, namely FTIR, NMR and CHN analysis. CHN, analytical calculated/found values for the synthesized inhibitor with the chemical formula $\mathrm{C}_{12} \mathrm{H}_{10} \mathrm{~N}_{4} \mathrm{O}_{2} \mathrm{~S}: \mathrm{C}, 52.54 / 52.31 ; \mathrm{H}, 3.67 / 3.29 ; \mathrm{N}$, 20.43/20.17. FT-IR $\left(\mathrm{cm}^{-1}\right.$ ): 3287.5, 3172.7 and 3161.3 (amino groups), 2911.6 (methylene group), 1713.8 (carbonyl group). ${ }^{1} \mathrm{H}-\mathrm{NMR}$ in DMSO- $\mathrm{d}_{6}(\mathrm{ppm}): \mathrm{d}, 1 \mathrm{H}, 7.31, \mathrm{~J}=7.84,1.34$; $\mathrm{d}$, $1 H, 7.39, \mathrm{~J}=8.33,1.28 ; \mathrm{d}, 1 \mathrm{H}, 7.67, J=8.33,7.32 ; \mathrm{d}, 1 \mathrm{H}, 7.51, J=7.84,1.32$ (protons of aromatic ring); s, 1H, $5.93\left(=\mathrm{C}-\mathrm{H}\right.$ of coumarin), s, $5.16\left(\mathrm{NH}_{2}\right), \mathrm{s}, 4.012 \mathrm{H}\left(\mathrm{CH}_{2}\right) .{ }^{13} \mathrm{C}-\mathrm{NMR}$ in DMSO-d $\mathrm{d}_{6}$ (ppm): 39.4, 109.5, 115.3, 118.9, 121.9, 127.3, 132.8, 150, 153.6, 159.4, 176.2. Finally the new corrosion inhibitor HATC was synthesized by refluxing a mixture of ATMC $(0.03 \mathrm{mmol})$ and 4-hydroxy-3-methoxybenzaldehyde $(0.03 \mathrm{mmol})$ in alcohol $(100 \mathrm{~mL})$ for 1 hours, then a few drops of acetic acid were added and the reflux was continued for another 7 hours. The mixture was cooled, filtered and dried. The precipitate was recrystallized from a mixture of DMF and EtOH to afford HATC as a new corrosion inhibitor. The yield of yellow powder was $77 \%$. Melting point: $243^{\circ} \mathrm{C}$. The chemical structure of the synthesized inhibitor was demonstrated in Scheme 1. CHN, analytical calculation/found values for the synthesized inhibitor with the chemical formula $\mathrm{C}_{20} \mathrm{H}_{16} \mathrm{~N}_{4} \mathrm{O}_{2} \mathrm{~S}: \mathrm{C}, 58.81 / 59.27 ; \mathrm{H}, 3.95 / 3.78$; $\mathrm{N}, 13.72 / 14.05$. FT-IR $\left(\mathrm{cm}^{-1}\right): 3314.8$ for amino group, 3199.3 for hydroxy group, 3071.1 for benzene ring, 2932.8 for methyl group, 1719.6 for carbonyl group and 1637.9 for azomethine group. ${ }^{1} \mathrm{H}$ NMR: $\delta 3.74\left(\mathrm{~s}, 2 \mathrm{H}, \mathrm{CH}_{2}\right), 3.94\left(\mathrm{~s}, 3 \mathrm{H}, \mathrm{OCH}_{3}\right), 6.07(\mathrm{~s}, 1 \mathrm{H}, \mathrm{C}-\mathrm{H})$, 6.90-7.18 (m, 1H, aromatic-H), $7.27(\mathrm{dd}, 1 \mathrm{H}), 7.30(1 \mathrm{H}, \mathrm{d}$, coumarin-H), $7.97(\mathrm{~s}, 1 \mathrm{H}, \mathrm{OH})$ and $8.75(\mathrm{~s}, 1 \mathrm{H}, \mathrm{NH}) .{ }^{13} \mathrm{C}$ NMR: $\delta 174.94(\mathrm{C}=\mathrm{O}), 160.28(\mathrm{C}=\mathrm{S}), 153.77,159.02,149.79$, $147.55,146.23,145.71,131.88,127.03,126.12$, 124.11, 122.89, 117.66, 115.87, 114.73, $114.26,110.82,56.48$ and 30.72 .

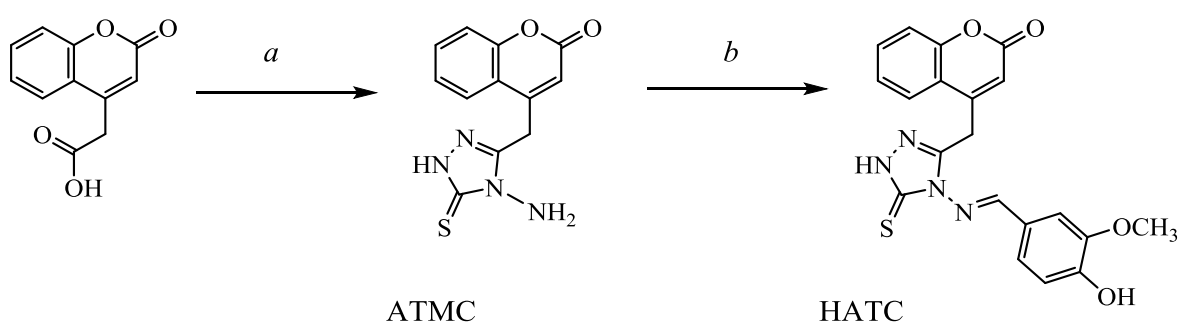

$a=$ hydrazinecarbothiohydrazide, Phosphorusoxychloride; $b=4$-hydroxy-3-methoxybenzaldehyde

Scheme 1. Chemical structure of the synthesized inhibitor. 


\subsection{Materials and corrosion tests}

A sample of mild steel with the following composition (\% by weight) was used: $99.21 \%$ Fe; $0.21 \% \mathrm{C} ; 0.38 \% \mathrm{Si} ; 0.09 \% \mathrm{P} ; 0.05 \% \mathrm{~S} ; 0.05 \% \mathrm{Mn}$ and $0.01 \%$ Al. Mild steel was mechanically cut and grounded by emery papers. The mild steel coupons were washed in acetone and distilled water, then dried and used. The acidic environment was prepared at a concentration of $1.5 \mathrm{M} \mathrm{HCl}$ by diluting concentrated hydrochloric acid (37\%) with distilled water. The corrosion inhibitor was used in different concentrations $(0.1,0.2,0.3,0.4$ and $0.5 \mathrm{mM})$.

\subsection{Weight loss measurements}

Weight loss tests were conducted using the method described in the literature $[43,44]$. Weight loss calculations were carried out at 303, 313, 323 and $333 \mathrm{~K}$ for 1, 3, 5, 10 and 24 hours, by immersing mild steel specimens in an acidic environment without and with different concentrations of the inhibitor. Specimens were ejected, washed, dried and weighed accurately. The corrosion rate $(C R)$ in mpy, inhibition efficiency $(I E \%)$ and surface coverage $(\theta)$ were calculated by equations $1-3$ :

$$
\begin{gathered}
C R=\frac{87.6 \mathrm{~W}}{t A d} \\
I E \%=\frac{C R_{0}-C R_{i n}}{C R_{0}} \times 100 \\
\theta=\frac{C R_{0}-C R_{\text {in }}}{C R_{0}}
\end{gathered}
$$

where $W$ is the weight loss of coupons, $A$ is the area of coupons, $d$ is the density, and $\mathrm{t}$ is the immersion time.

The same process was repeated for temperature studies with the immersion period of 5 hours. (Note: Eq. 3 is only valid for inhibitors with blocking action).

\subsection{Quantum Chemical Calculations}

The quantum chemical calculations of the new inhibitor molecules were made using the density functional theory (DFT), which includes the three hybrid functions of Becke parameters with the Lee-Yang-Parr functional binding function (B3LYP) [45]. The base group 6-31G(d,p) was used for all calculations. The calculations were made without parity restrictions using Gaussian 03, version E.01 [46]. The parameters such as the energy of the highest occupied molecular orbital $\left(E_{\text {HОмо }}\right)$, lowest unoccupied molecular orbital $\left(E_{\mathrm{LUMO}}\right)$, energy gap $(\Delta E)$, dipole moment $(\mu)$, global softness $(\sigma)$, global hardness $(\eta)$, electrophilicity $(\omega)$, fraction of electrons transferred $(\Delta N)$, and electronegativity $(\chi)$ were calculated [42]. 
Table 1 shows how these parameters are calculated.

\begin{tabular}{|c|c|c|}
\hline Parameter & Definition & Calculation method \\
\hline$\Delta E$ & Energy gap & $\Delta E=E_{\mathrm{HOMO}}-E_{\mathrm{LUMO}}$ \\
\hline$\chi$ & $\begin{array}{l}\text { Electronegativity }(\chi) \text { is a chemical property } \\
\text { that describes the tendency of an atom to } \\
\text { attract a shared pair of electrons (or } \\
\text { electron density) towards itself. }\end{array}$ & $\chi=-1 / 2 \cdot\left(E_{\mathrm{HOMO}}+E_{\mathrm{LUMO}}\right)$ \\
\hline$\eta$ & $\begin{array}{l}\text { Global hardness is the resistance of an } \\
\text { atom to a charge transfer }\end{array}$ & $\eta=-1 / 2 \cdot\left(E_{\mathrm{HOMO}}-E_{\mathrm{LUMO}}\right)$ \\
\hline$\omega$ & Global electrophilicity index & $\omega=\chi^{2} / 2 \eta$ \\
\hline$\sigma$ & $\begin{array}{l}\text { Global softness is capacity of an atom (or } \\
\text { atoms) to receive electrons }\end{array}$ & $\sigma=1 / \eta=-2 /\left(E_{\mathrm{HOMO}}-E_{\mathrm{LUMO}}\right)$ \\
\hline$\Delta N$ & $\begin{array}{l}\text { The fraction of electrons transferred [59] } \\
\text { from the inhibitor to the Fe atom }\end{array}$ & $\Delta N=\frac{\chi_{\mathrm{Fe}}-\chi_{\mathrm{inh}}}{2\left(\eta_{\mathrm{Fe}}+\eta_{\mathrm{inh}}\right)}$ \\
\hline
\end{tabular}

The $\chi_{\mathrm{Fe}}$ was equated to $7 \mathrm{eV} / \mathrm{mol}$ and $\eta_{\mathrm{Fe}}$ was equated to $0 \mathrm{eV} / \mathrm{mol}$.

To detect the atomic active sites of HATC molecules, Fukui functions $(f(\mathbf{r}))$ were effectively utilized $[47,48]$. The $(f(\mathbf{r}))$ refer to the variation in the $N$-electron density system of an electron which is added $\left(f^{+}(\mathbf{r})\right)$ or removed $\left(f^{-}(\mathbf{r})\right)$ [49]. Equations 4 and 5 were used to calculate the Fukui indices condensed $\left(f^{+} k\right.$ and $\left.f^{-} k\right)$ on atom $k$.

$$
\begin{aligned}
& f^{+} k=\rho k(N+1)(r)-\rho k(N)(r) \\
& f^{-} k=\rho k(N)(r)-\rho k(N-1)(r)
\end{aligned}
$$

Where $\rho k_{(N+1)}$ is the electron densities of $(N+1)$, and $\rho k_{(N-1)}$ is the electron density of $(N-1)$.

\section{Results and Discussion}

\subsection{Characterization of ATMC and HATC}

The chemical structures of ATMC and HATC were elucidated by FTIR, ${ }^{1} \mathrm{H}-\mathrm{NMR}$, ${ }^{13} \mathrm{C}$-NMR and $\mathrm{CHN}$ techniques. The FTIR $\left(\mathrm{cm}^{-1}\right)$ spectrum of ATMC shows significant bands corresponding to $v(\mathrm{~N}-\mathrm{H}$, asym), $v(\mathrm{~N}-\mathrm{H}, \operatorname{sym}), v(\mathrm{C}-\mathrm{H})$ and $\mathrm{v}(\mathrm{C}=\mathrm{O})$ at 3287.5, $3172.73161 .3,2911.6,1713.8 \mathrm{~cm}^{-1}$, respectively. The ${ }^{1} \mathrm{H}$ NMR (DMSO-d $\mathrm{d}_{6}, \delta, \mathrm{ppm}$ ) of ATMC shows significant bands: a singlet at $4.01 \mathrm{ppm}$ from two protons of methylene group, another singlet signal at $5.93 \mathrm{ppm}$ due to the single proton of the pyronering $(=\mathrm{C}-\mathrm{H}$ of coumarin). The singlet signal at $5.16 \mathrm{ppm}$ was from the two protons of the amino group. Finally, the aromatic ring has doublet signals of one proton at 7.31, 7.39, 7.67 and 7.521. ${ }^{13} \mathrm{C}-\mathrm{NMR}$ bands in DMSO-d $\mathrm{d}_{6}(\mathrm{ppm})$ were found at 39.4, 109.5, 115.3, 118.9, 121.9, 127.3, 
132.8, 150, 153.6, 159.4 and 176.2. These bands confirm the structure of the ATMC molecule and this is another confirmation of the synthesis of ATMC as a precursor for HATC. The FTIR $\left(\mathrm{cm}^{-1}\right)$ spectrum of HATC shows significant bands corresponding to $v(\mathrm{~N}-\mathrm{H}), v(\mathrm{O}-\mathrm{H}), v(\mathrm{C}-\mathrm{H}$, aromatic $), v(\mathrm{C}-\mathrm{H}$ aliphatic $), v(\mathrm{C}=\mathrm{O})$ and $\mathrm{v}(\mathrm{C}=\mathrm{N})$ at 3314.8, $3199.3,3071.1,2932.8,1719.6$ and $1637.9 \mathrm{~cm}^{-1}$, respectively.

The ${ }^{1} \mathrm{H}$ NMR (DMSO- $\mathrm{d}_{6}, \delta$, ppm) of HATC shows significant bands: a singlet at 3.74 ppm from two protons of the methylene group and $3.94 \mathrm{ppm}$ from three protons of the methoxide group, other singlet signals at 7.97 and $8.75 \mathrm{ppm}$ due to single protons of the hydroxy group and amino group, $7.30 \mathrm{ppm}$ from the single proton of the pyrone ring $(=\mathrm{C}-\mathrm{H}$ of coumarin $)$. Finally, the aromatic ring has singlet, multiplet and doublet signals from one proton at $6.07,6.90-7.18,7.27 \mathrm{ppm}$ respectively. ${ }^{13} \mathrm{C}-\mathrm{NMR}$ bands in DMSO- $\mathrm{d}_{6}$ $(\mathrm{ppm})$ were found at $\delta 174.94(\mathrm{C}=\mathrm{O}), 160.28(\mathrm{C}=\mathrm{S}), 153.77,159.02,149.79,147.55$, $146.23,145.71,131.88,127.03,126.12,124.11,122.89$, 117.66, 115.87, 114.73, 114.26, $110.82,56.48$ and 30.72. These bands confirm that the number of carbon atoms was twenty and this is another confirmation that HATC was synthesized.

\subsection{Gravimetric method}

Weight loss measurements were performed on mild steel submerged in $1.0 \mathrm{M} \mathrm{HCl}$ for $(1,5,10$ and 24) hours in the absence of different concentrations of HATC. Experiments were conducted at different temperatures.

\subsection{Effect of the inhibitor concentration, immersion time and temperature}

Figure 1 demonstrates the effect of HATC concentration on the corrosion rates at $303 \mathrm{~K}$ for the period 1, 5, 10, 24, 48 and 72 hours in hydrochloric acid environment. The corrosion rate decreases with concentration increase due to the presence of a considerable number of adsorption sites which were brought through significant HATC concentrations. The differences in corrosion rates (CRs) at various concentrations of HATC inhibitor molecules for immersion time of 1-24 hours in $\mathrm{HCl}$ solution at $303 \mathrm{~K}$ are shown in Figure 1. 


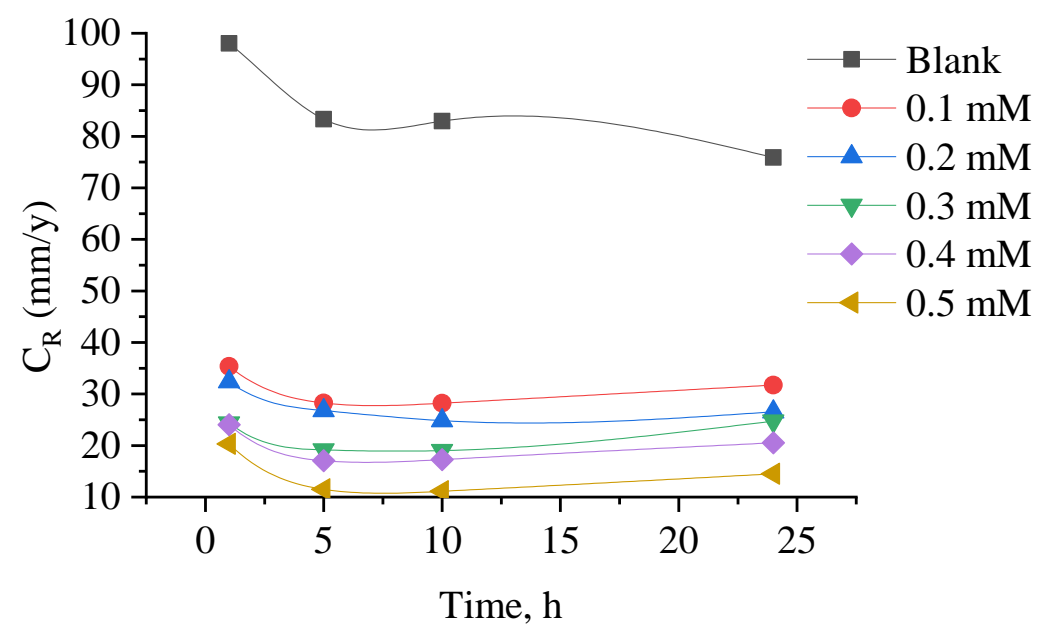

Figure 1. Effect of HATC concentration and time on the corrosion rate of mild steel.

The percentage inhibition efficiency (IE\%) of HATC as a corrosion inhibitor was calculated at different concentrations $(1.0,2.0,3.0,4.0$ and 5.0) $\mathrm{mM}$, immersion times $(1,5,10$ and 24) $\mathrm{h}$ and temperatures $(303,313,323$ and 333) K. Plots of $C R$ and $I E \%$ versus HATC concentrations at different times are shown in Figures 1 and 2. The plots of IE\% versus HATC concentrations at different temperatures are shown in Figure 3. The results demonstrate that $I E \%$ increases with increasing concentration and decreases with increasing time (after 10 hours). Also, IE\% decreases with increasing temperature.

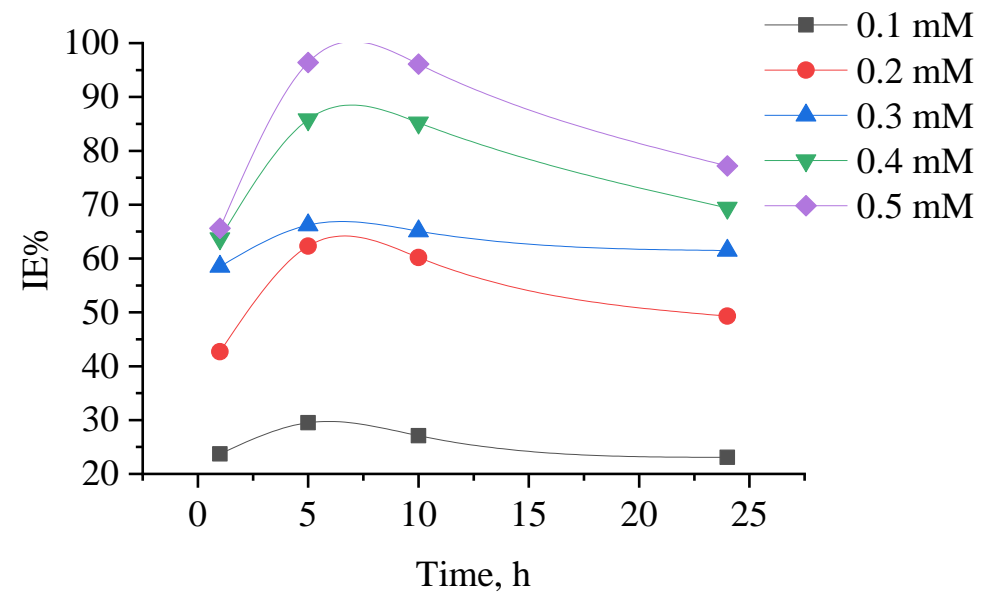

Figure 2. Effect of MS immersion time in the corrosive environment at various concentrations of HATC.

One characteristic shown in Figure 2 is the variation in the direction of the $I E \%$ of the corrosion inhibitor studied at high and low concentrations. For example, at a time of immersion for a period of 5 and 10 hours approximately the same values of $I E \%$ at concentrations of 0.4 and $0.5 \mathrm{mM}$ at the same temperature (at $303 \mathrm{~K}$ ) were found, but the inhibition efficiencies varied at the other concentration and in all cases the inhibition efficiencies decrease after 24 hours. 


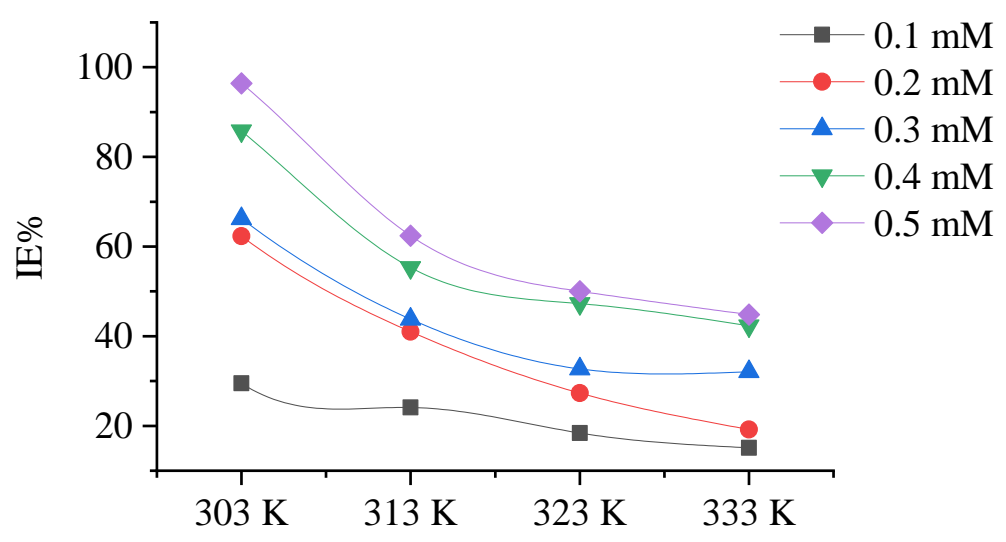

Temperature, $\mathrm{K}$

Figure 3. Effect of temperature on $I E$ of HATC in $1 \mathrm{M} \mathrm{HCl}$.

As demonstrated in Figure 3, the effect of temperature on the surface of mild steel in a corrosive environment in the presence of the corrosion inhibitor is quite complex due to the fact that with increase in temperature, etching and desorption of inhibitor occur, as a consequence of that additional metal surface is coming into contact with the acidic environment which increases the $C R$. The dissolution of the mild steel surface may hinder the corrosion rate and thus decompose the layer that protects the surface.

\subsection{Thermodynamic and Activation Parameters}

Adsorption is an important process in inhibiting the corrosion of mild steel surface because corrosion inhibition is often carried out using organic compounds. The mechanism of inhibition can be identified by determining inhibitor behavior through studying and understanding the thermodynamics of the adsorption process. Corrosion rate depends on temperature as it can be demonstrated by Arrhenius equation (Equation 6):

$$
\log C R=\log A-\frac{E_{a}}{2.303 R T}
$$

Where $C R\left(\mathrm{~g} \cdot \mathrm{cm}^{-2} \cdot \mathrm{h}^{-1}\right)$ is the corrosion rate, $A$ is a constant, $E_{a}$ is the activation energy, $R\left(8.314 \mathrm{~J} \cdot \mathrm{K}^{-1} \mathrm{~mol}^{-1}\right)$ is the gas constant and $T$ is the absolute temperature.

The activation enthalpy $\left(\Delta H^{*}\right)$ and entropy $\left(\Delta S^{*}\right)$ values were calculated from the transition state as in Equation 7:

$$
\log \left(\frac{C R}{T}\right)=\left[\log \left(\frac{R}{N h}\right)+\left(\frac{\Delta S^{*}}{2.303 R}\right)\right]+\left(-\frac{\Delta H^{*}}{2.303 R}\right)\left(\frac{1}{T}\right)
$$

where $h$ is Planck's constant and $N$ is Avogadro number.

Figure 4 demonstrates the activation energy and it was calculated from the Arrhenius equation and slope value, in the presence and absence of HATC. The value of activation energy for hydrochloric acid solution without HATC is $32 \mathrm{~kJ} / \mathrm{mol}$, while in the presence of 
HATC as a corrosion inhibitor it is $61.73 \mathrm{~kJ} / \mathrm{mol}$. The high value of activation energy of HATC implies that the HATC molecules form a layer that protects the surface of mild steel from the corrosive solution.

Table 2. Kinetic parameters for MS in $1.0 \mathrm{M} \mathrm{HCl}$ in the presence and absence of HATC.

\begin{tabular}{cccc}
\hline $\begin{array}{c}\text { Conc. } \\
\mathbf{~ m M}\end{array}$ & $\begin{array}{c}\boldsymbol{E}_{\boldsymbol{a}} \\
\left(\mathbf{k J} \cdot \mathbf{m o l}^{\mathbf{- 1}}\right)\end{array}$ & $\begin{array}{c}\Delta \boldsymbol{H}_{\boldsymbol{a}} \\
\left(\mathbf{k J} \cdot \mathbf{m o l}^{-\mathbf{1}}\right)\end{array}$ & $\begin{array}{c}\Delta \boldsymbol{S}_{\boldsymbol{a}} \\
\left(\mathbf{J} \cdot \mathbf{m o l}^{-\mathbf{1}} \cdot \mathbf{K}^{\mathbf{- 1}}\right)\end{array}$ \\
\hline 0.0 & 55.9 & 51.0 & -66.7 \\
0.1 & 77.2 & 76.8 & -155.1 \\
0.3 & 83.4 & 82.5 & -167.4 \\
0.5 & 90.2 & 88.0 & -178.4 \\
\hline
\end{tabular}

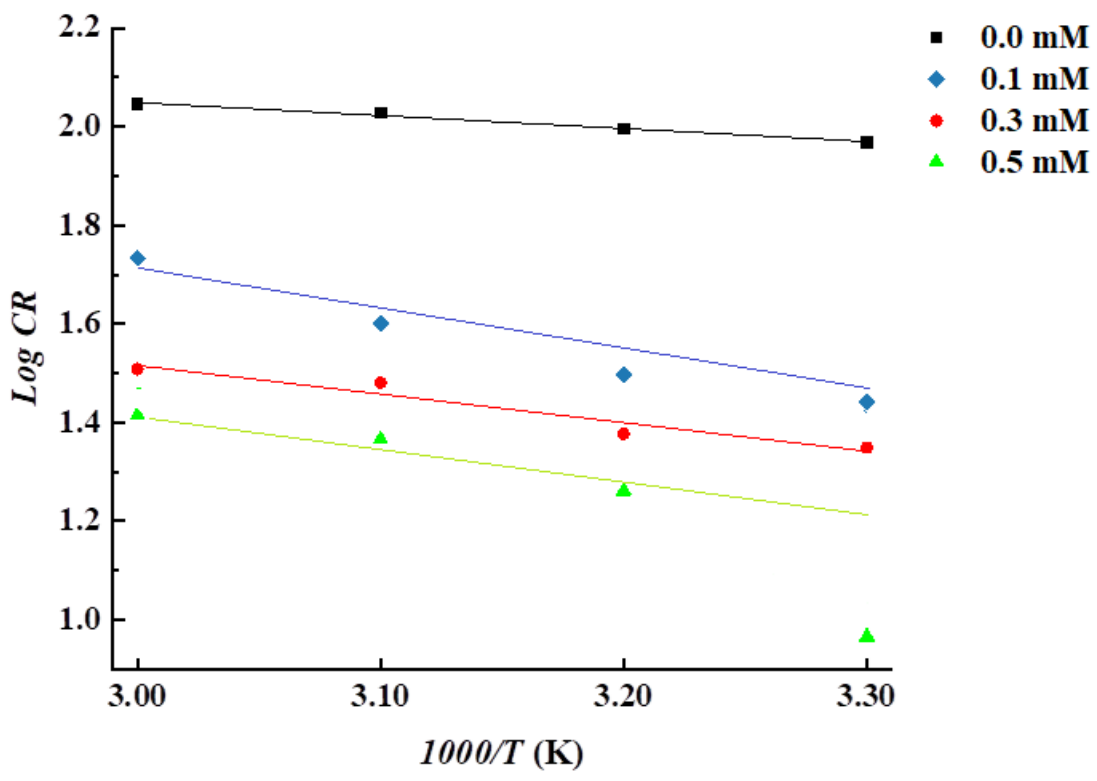

Figure 4. Arrhenius plot for mild steel in $1 \mathrm{M} \mathrm{HCl}$ in the presence and absence of HATC.

In Table 2, $\Delta H$ with a positive value refers to an endothermic dissolution process for surface of mild steel at room temperature in the presence of HATC molecules. $\Delta H$ increased with a temperature increase, which supports the endothermic nature of MS surface dissolution and the decrease of the inhibition performance of HATC molecules. The entropy activation values at room temperature were negative and became positive with increasing temperature. In the absence of HATC molecules, the entropy activation values were positive and tended to be negative at higher concentrations of HATC. A negative activation entropy value indicated that, at room temperatures and the maximum concentration of HATC studied, the MS surface was protected by the HATC molecules.

Langmuir, Temkin, and Frumkin absorption isotherms were used to realize the adsorption nature of HATC molecules as inhibitor for the corrosion of mild steel (MS) 
surface. Figure 4 agrees with the Langmuir isotherm with a slope coefficient value less than one. The Langmuir adsorption isotherm is represented by Equation 8 .

$$
\frac{C}{\theta}=\frac{1}{K_{\text {ads }}}+C
$$

Figure 5 demonstrates the slope of straight line for the value concentration/surface coverage versus concentration. The intercept value represents the adsorption equilibrium constant that indicates a high absorption rate of HATC molecules on the MS surface [47].

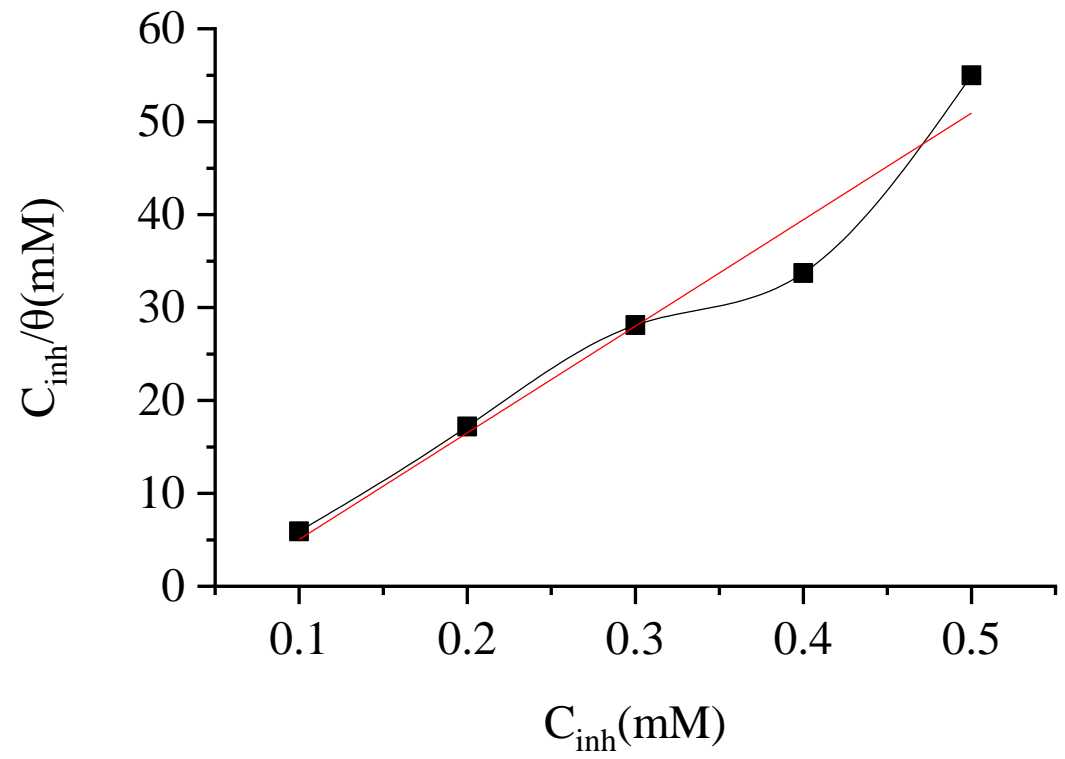

Figure 5. Langmuir adsorption isotherm plot for HATC in acidic environment on MS surface.

The $K_{\text {ads }}[48,49]$ is correlated with the free energy of adsorption $\left(\Delta G_{\text {ads }}^{0}\right)$ as in Equation 9.

$$
\Delta G_{\mathrm{ads}}^{0}=-R T \ln \left(1000 K_{\mathrm{ads}}\right)
$$

In the present study, the $\Delta G_{\text {ads }}^{0}$ value of HATC was $-32.85 \mathrm{~kJ} / \mathrm{mol}$. This value elucidates that HATC is adsorbed on the MS surface spontaneously and approaches a mixed adsorption type.

\subsection{Quantum Chemical Calculation}

The quantum chemical parameters (QCPs) for the neutral form of the investigated inhibitor calculated by DFT/B3LYP with the $6-31+\mathrm{G}(\mathrm{d})$ are listed in Table 3. Analysis of the data will be given in the following paragraphs. The highest occupied molecular orbital (HOMO), the lowest unoccupied molecular orbital (LUMO) and their effective part in chemical reactivity were also calculated [50]. Moreover $E_{\mathrm{HOMO}}, E_{\mathrm{LUMO}}$, Hardness ( $)$, 
Electrophilicity $(\omega)$, Ionization Potential $(I)$, Dipole Momentum $(\mu \mathrm{D})$, Atomic charges $(q)$ and Proton affinities $(P A)$ were considered as indicators of activity. Herein we utilized quantum chemistry to realize the relationship between inhibitor molecules and inhibition efficiency. The geometrical structure of the tested inhibitor was investigated, which confirmed the $I E$ values obtained from experimental results.

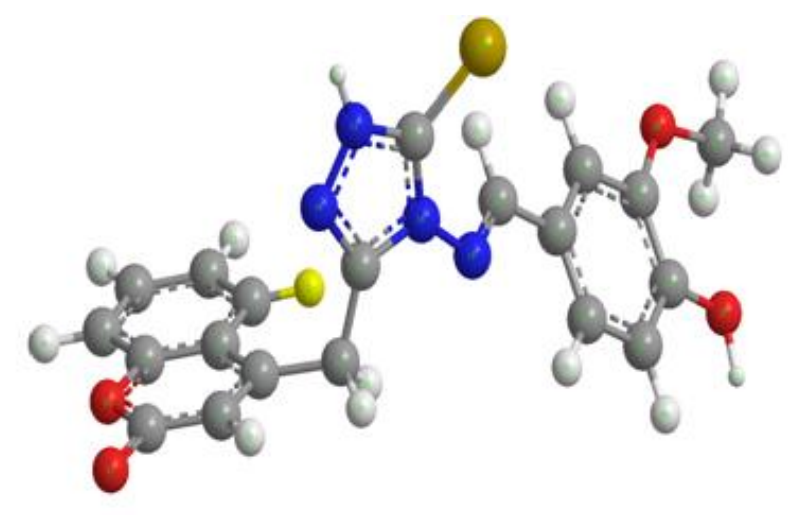

Optimized structure of HATC

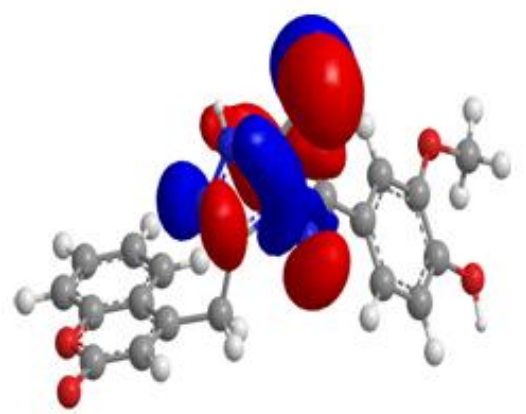

HOMO -8.194

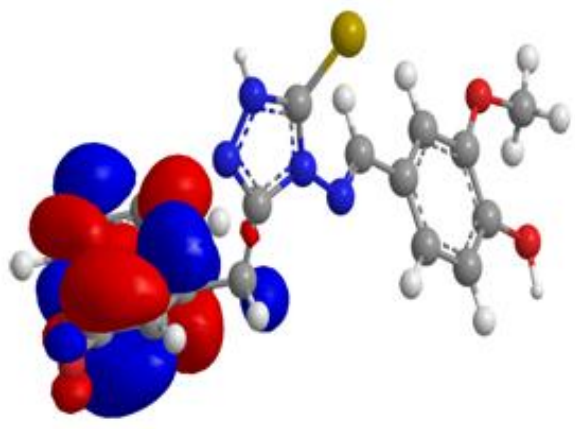

LUMO -5.49

Figure 6. Optimized structure, HOMO and LUMO for HATC.

The adsorption capability of the inhibitor molecules over a mild steel surface coupon is associated with HOMO and LUMO [41, 42]. HOMO is related to the capability of a molecule to contribute electrons, on the other hand, LUMO refers to the ability to accept electrons. From Figure 6, it is obvious that HOMO and LUMO electronic densities on the entire inhibitor molecule are completely steady because of Pi-electrons.

As in Figure 6, the analysis of frontier orbitals, HOMO and LUMO demonstrate that significant nucleophilic sites attack atoms of coumarin and triazole rings and these heteroatoms have the ability to interact with mild steel surface [51]. HOMO and LUMO are related with the abilities of donating and accepting electrons, respectively. A high value 
of $E_{\mathrm{HOMO}}$ facilitates adsorption through influencing the donation process by the adsorbed film $[52,53]$.

An energy gap with low values is a significant indicator of excellent inhibition efficiency, due to low energy required to remove electrons from an occupied orbital [54]. The energy gap was also found to be $2.7 \mathrm{eV}$ as in Table 3 , which reveals that the synthesized corrosion inhibitor has a good inhibition efficiency. Hard molecules have big energy gaps, and hard molecules are less reactive than soft molecules $[55,56]$.

Another quantum parameter significant for corrosion inhibition efficiency was the dipole moment $(\mu)$. It is the related with the electrons distribution and bond polarity [57]. The hardness and softness can be related to the $E_{\mathrm{HOMO}}$ and $E_{\mathrm{LUMO}}[58]$.

Table 3. Computed parameters for HATC.

\begin{tabular}{cc}
\hline Parameter & Value \\
\hline$\Delta E$ & -2.704 \\
HOMO & -8.194 \\
LUMO & -5.490 \\
$I$ & 8.194 \\
$A$ & 5.490 \\
$\mu$ & 5.03 \\
$\chi$ & 5.842 \\
$\eta$ & 1.352 \\
$\omega$ & 12.62 \\
$\sigma$ & 0.739 \\
$\Delta N$ & 0.82 \\
\hline
\end{tabular}

HATC is a new synthesized corrosion inhibitor with the smallest value of hardness $1.352(\mathrm{eV})$. The corrosion inhibitor with a low hardness value is predicated to have an excellent inhibition efficiency [59]. For the easy electron transfer, adsorption occurs at the site of the molecule that has a high value of softness $(\sigma)[60]$. HATC has a softness value of $0.739 \mathrm{eV}$, so this tested inhibitor has a superior inhibition efficiency. $\Delta N$ was calculated according to Table 1 using theoretical values of $\chi$ and $\eta$ for iron that are $7 \mathrm{eV} / \mathrm{mol}$ and $0 \mathrm{eV} / \mathrm{mol}$, respectively. The $\Delta N$ value demonstrated the inhibition impact resulting from donation of electrons that agrees with Lukovits et al.'s investigation [40]. If the value of $\Delta N$ is $<3.6$, the $I E \%$ increases with the ability of electron donation at the surface of mild steel. The higher the value of $\Delta N$, the higher the IE\% and hence the better the compound as inhibitor. 


\section{Conclusion}

The results of the this study revaled that the new eco-friendly coumarin derivative, namely, 4-((4-((4-hydroxy-3-methoxybenzylidene)amino)-5-thioxo-4,5-dihydro-1 H-1,2,4-triazol-3yl)methyl)-coumarin (HATC), acted as a superior corrosion inhibitor for mild steel surface in corrosive acidic environment in a concentration-dependent technique. HATC has an excellent inhibition efficiency of $96 \%$ at a concentration of $0.5 \mathrm{mM}$, which decreases with an increase in temperature, which indicates physisorption. HATC molecules were adsorbed on mild surface surface obeying the Langmuir adsorption isotherm. The high inhibition efficiency of HATC molecules wasdue to the presence of nitrogen, sulphur and oxygen atoms in addition to benzene, lactone and triazole rings. The corrosion inhibition investigation of HATC molecules obviously implied its role in the protection of mild steel surface in hydrochloric acid solutions.

\section{Acknowledgement}

This study was supported by the University of Technology, Baghdad, Iraq.

\section{Conflicts of Interest}

The authors declare no conflict of interest.

\section{References}

1. X. Li, S. Deng, H. Fu and T. Li, Adsorption and inhibition effect of 6-benzylaminopurine on cold rolled steel in $1.0 \mathrm{M} \mathrm{HCl}$, Electrochim. Acta, 2009, 54, 4089-4098. doi: $10.1016 /$ j.electacta.2009.02.084

2. I.A. Zaafarany, Corrosion Inhibition of Mild Steel in Hydrochloric Acid Solution using Cationic Surfactant Olyel-amido Derivatives, Int. J. Electrochem. Sci., 2013, 8, 9531-9542.

3. X. Chen, X.G. Li, C.W. Du and Y.F. Cheng, Effect of cathodic protection on corrosion of pipeline steel under disbonded coating, Corros. Sci., 2009, 51, 2242-2245. doi: 10.1016/j.corsci.2009.05.027

4. A. Mahmoodi and M. Ebrahimi, Role of a hybrid dye-clay nano-pigment (DCNP) on corrosion resistance of epoxy coatings, Prog. Org. Coat., 2018, 114, 223-232. doi: 10.1016/j.porgcoat.2017.10.022

5. A. Yabuki, S. Tanabe and I.W. Fathona, Self-healing polymer coating with the microfibers of superabsorbent polymers provides corrosion inhibition in carbon steel, Surf. Coat. Technol., 2018, 341, 71-77. doi: 10.1016/j.surfcoat.2017.08.030

6. S.B. Lyon, R. Bingham and D.J. Mills, Advances in corrosion protection by organic coatings: What we know and what we would like to know, Prog. Org. Coat., 2017, 102, 2-7. doi: 10.1016/j.porgcoat.2016.04.030 
7. H.H. Zhang, Y. Chen and Z.Zhang, Comparative studies of two benzaldehyde thiosemicarbazone derivatives as corrosion inhibitors for mild steel in $1.0 \mathrm{M} \mathrm{HCl}$, Results Phys., 2018, 11, 554-563. doi: 10.1016/j.rinp.2018.09.038

8. T.A. Salman, K.F. Al-Azawi, I. Mahdi, S.B. Al-Baghdadi, A.A. Al-Amiery, T.S. Gaaz and A.H. Kadhum, Experimental studies on inhibition of mild steel corrosion by novel synthesized inhibitor complemented with quantum chemical calculations, Results Phys., 2018, 10, 291-296. doi: 10.1016/j.rinp.2018.06.019

9. Y. Chen, Y.Y. Jiang, H. Chen, Z. Zhang, J.Q. Zhang and C.N. Cao, Corrosion Inhibition of Mild Steel in Acidic Medium by Linseed Oil-Based Imidazoline, J. Am. Oil Chem. Soc., 2013, 90, 9, 1387-1395. doi: 10.1007/s11746-013-2283-3

10. N.A. Odewunmi, S.A. Umoren, Z.M. Gasem, S.A. Ganiyu and Q. Muhammad, 1-Citrulline: An active corrosion inhibitor component of watermelon rind extract for mild steel in $\mathrm{HCl}$ medium, J. Taiwan Inst. Chem. Eng., 2015, 51, 177-185. doi: 10.1016/j.jtice.2015.01.012

11. A. Zeino, I. Abdulazeez, M. Khaled, M.W. Jawich and I.B. Obot, Mechanistic study of polyaspartic acid (PASP) as eco-friendly corrosion inhibitor on mild steel in 3\% $\mathrm{NaCl}$ aerated solution, J. Mol. Liq., 2018, 250, 50-62. doi: 10.1016/j.molliq.2017.11.160

12. S. Hejazi, Sh. Mohajernia, M.H. Moayed, A. Davoodi, M. Rahimizadeh, M. Momeni, A. Eslami, A. Shiri and A. Kosari, Electrochemical and quantum chemical study of Thiazolo-pyrimidine derivatives as corrosion inhibitors on mild steel in $1 \mathrm{M} \mathrm{H}_{2} \mathrm{SO}_{4}$, J. Ind. Eng. Chem., 2015, 25, 112-121. doi: 10.1016/j.jiec.2014.10.020

13. J. Haque, C. Verma, V. Srivastava, M.A. Quraishi and E.E. Ebenso, Experimental and quantum chemical studies of functionalized tetrahydropyridines as corrosion inhibitors for mild steel in $1 \mathrm{M}$ hydrochloric acid, Results Phys., 2018, 9, 1481-1493. doi: 10.1016/j.rinp.2018.04.069

14. A.A. Farag and T.A. Ali, The enhancing of 2-pyrazinecarboxamide inhibition effect on the acid corrosion of carbon steel in presence of iodide ions, J. Ind. Eng. Chem., 2015, 21, 627-634. doi: 10.1016/j.jiec.2014.03.030

15. C. Verma, E.E. Ebenso, I. Bahadur, I.B. Obot and M.A. Quraishi, 5-(Phenylthio)-3Hpyrrole-4-carbonitriles as effective corrosion inhibitors for mild steel in $1 \mathrm{M} \mathrm{HCl}$ : Experimental and theoretical investigation, J. Mol. Liq., 2015, 212, 209-218. doi: 10.1016/j.molliq.2015.09.009

16. R. Hasanov, S. Bilge, S. Bilgiç, G. Gece and Z. Kılıç, Experimental and theoretical calculations on corrosion inhibition of steel in $1 \mathrm{M} \mathrm{H}_{2} \mathrm{SO}_{4}$ by crown type polyethers, Corros. Sci., 2010, 52, no. 3, 984-990. doi: 10.1016/j.corsci.2009.11.022

17. S. Junaedi, A. Kadhum, A. Al-Amiery, A. Mohamad and M. Takriff, Synthesis and characterization of novel corrosion inhibitor derived from oleic acid: 2-Amino5-Oleyl1,3,4-Thiadiazol (AOT), Int. J. Electrochem Sci., 2012, 7, 3543-3554.

18. A.A. Al-Amiery, A.A.H. Kadhum, A.B. Mohamad and S. Junaedi, A Novel Hydrazinecarbothioamide as a Potential Corrosion Inhibitor for Mild Steel in $\mathrm{HCl}$, Materials, 2013, 6, 1420-1431. doi: 10.3390/ma6041420 
19. A. Al-Amiery, A. Kadhum, A. Mohamad, A. Musa and C. Li, Electrochemical study on newly synthesized chlorocurcumin as an inhibitor for mild steel corrosion in hydrochloric acid, Materials, 2013, 6, 5466-5477. doi: 10.3390/ma6125466

20. H. Cang, Z. Fei, W. Shi, and Q. Xu, Experimental and theoretical study for corrosion inhibition of mild steel by L-Cysteine, Int. J. Electrochem. Sci., 2012, 7, 10121-10131.

21. A.A.H. Kadhum, A.B. Mohamad, L.A. Hammed, A.A. Al-Amiery, N.H. San and A.Y. Musa, Inhibition of Mild Steel Corrosion in Hydrochloric Acid Solution by New Coumarin, Materials, 2014, 7, 4335-4348. doi: 10.3390/ma7064335

22. A.A. Al-Amiery, A.A.H. Kadhum, A. Kadihum, A.B. Mohamad, C.K. How and S. Junaedi, Inhibition of Mild Steel Corrosion in Sulfuric Acid Solution by New Schiff Base, Materials, 2014, 7, 787-804. doi: 10.3390/ma7020787

23. A.A. Al-Amiery, A.A. H. Kadhum, A.H.M. Alobaidy, A.B. Mohamad and P.S. Hoon, Novel Corrosion Inhibitor for Mild Steel in HCl, Materials, 2014, 7, 662-672. doi: 10.3390/ma7020662

24. A. Mohamad, A. Kadhum, A. Al-Amiery, L. Ying and A. Musa, Synergistic of a coumarin derivative with potassium iodide on the corrosion inhibition of aluminum alloy in $1.0 \mathrm{M} \mathrm{H}_{2} \mathrm{SO}_{4}$, Met. Mater. Int., 2014, 20, 459-467. doi: 10.1007/s12540-0143008-3

25. H.R. Obayes, G.H. Alwan, A.H.M. Alobaidy, A.A. Al-Amiery, A.A.H. Kadhum and A.B. Mohamad, Quantum chemical assessment of benzimidazole derivatives as corrosion Inhibitors, Chem. Cent. J., 2014, 8, 1-8. doi: 10.1186/1752-153X-8-21

26. A.A. Al-Amiery, Y.K. Al-Majedy, A.A.H. Kadhum and A.B. Mohamad, New Coumarin Derivative as an Eco-Friendly Inhibitor of Corrosion of Mild Steel in Acid Medium, Molecules, 2015, 20, 366-383. doi: 10.3390/molecules20010366

27. E. Yousif, Y. Win, A. Al-Hamadani, A. Al-Amiery, A. Kadhum and A. Mohamad, Furosemi as an environmental-friendly inhibitor of corrosion of zinc metal in acid medium experimental and theoretical studies, Int. J. Electrochem Sci., 2015, 10, $1708-1718$.

28. A.Y.I. Rubaye, A.A. Abdulwahid, S.B. Al-Baghdadi, A. Al-Amiery, A.A.H. Kadhum and A.B. Mohamad, Cheery sticks plant extract as a green corrosion inhibitor complemented with LC-EIS/MS spectroscopy, Int. J. Electrochem Sci., 2015, 10, 8200-8209.

29. A.H.M.J. Al-Obaidy, A. Kadhum, S.B. Al-Baghdadi, A. Al-Amiery, A.A.H. Kadhum, A.B. Mohamad and E. Yousif, Eco-friendly corrosion inhibitor: experimental studies on the corrosion inhibition performance of creatinine for mild steel in $\mathrm{HCl}$ complemented with quantum chemical calculations, Int. J. Electrochem Sci., 2015, 10, 3961-3972.

30. S.B. Al-Baghdadi, F.T.M. Noori, W.K. Ahmed and A.A. Al-Amiery, Thiadiazole as a Potential Corrosion Inhibitor for Mild Steel in $1 \mathrm{M} \mathrm{HCl}, J$. Adv. Electrochem., 2016, 2, 67-69. 
31. A.A. Al-Amiery, F.A.B. Kassim, A.A.H. Kadhum and A.B. Mohamad, Synthesis and characterization of a novel eco-friendly corrosion inhibition for mild steel in 1 M hydrochloric acid, Sci. Rep., 2016, 6, 19890. doi: 10.1038/srep19890

32. A. Kadhim, A. Al-Okbi, D.M. Jamil, A. Qussay, A.A. Al-Amiery, T.S. Gaaz, A.A.H. Kadhum, A.B. Mohamad and M.H. Nassir, Experimental and theoretical studies of benzoxazines corrosion inhibitors, Results Phys., 2017, 7, 4013-4019. doi: 10.1016/j.rinp.2017.10.027

33. H.R. Obayes, A.A. Al-Amiery, G.H. Alwan, T.A. Abdullah, A.A.H. Kadhum and A.B. Mohamad, Sulphonamides as corrosion inhibitor: Experimental and DFT studies, J. Mol. Struct., 2017, 1138, 27-34. doi: $\underline{10.1016 / j . m o l s t r u c .2017 .02 .100}$

34. S.B. Al-Baghdadi, F.G. Hashim, A.Q. Salam, T.K. Abed, T.S. Gaaz, A.A. Al-Amiery, A.A.H. Kadhum, K.S. Reda and W.K. Ahmed, Synthesis and corrosion inhibition application of NATN on mild steel surface in acidic media complemented with DFT studies, Results Phys., 2018, 8, 1178-1184. doi: 10.1016/j.rinp.2018.02.007

35. H.J. Habeeb, H.M. Luaibi, R.M. Dakhil, A.A.H. Kadhum, A.A. Al-Amiery and T.S. Gaaz, Development of new corrosion inhibitor tested on mild steel supported by electrochemical study, Results Phys., 2018, 8, 1260-1267. doi: 10.1016/j.rinp.2018.02.015

36. K.F. Al-Azawi, I.M. Mohammed, S.B. Al-Baghdadi, T.A. Salman, H.A. Issa, A.A. Al-Amiery, T.S. Gaaz and A.A.H. Kadhum, Experimental and quantum chemical simulations on the corrosion inhibition of mild steel by 3-((5-(3,5-dinitrophenyl)-1,3,4thiadiazol-2-yl)imino)indolin-2-one, Results Phys., 2018, 9, 278-283. doi: 10.1016/j.rinp.2018.02.055

37. D.M. Jamil, A.K. Al-Okbi, S.B. Al-Baghdadi, A.A. Al-Amiery, A. Kadhim and T.S. Gaaz, Experimental and theoretical studies of Schiff bases as corrosion inhibitors, Chem. Cent. J., 2018, 12, 1-7. doi: 10.1186/s13065-018-0376-7

38. M.H.O. Ahmed, A.A. Al-Amiery, Y.K. Al-Majedy, A.A.H. Kadhum, A.B. Mohamad and T.S. Gaaz, Synthesis and characterization of a novel organic corrosion inhibitor for mild steel in $1 \mathrm{M}$ hydrochloric acid, Results Phys., 2018, 8, 728-733. doi: 10.1016/j.rinp.2017.12.039

39. T.A. Salman, D.S. Zinad, S.H. Jaber, M. Al-Ghezi, A. Mahal, M.S. Takriff and A.A. Al-Amiery, Effect of 1,3,4 Thiadiazole Scafold on the Corrosion Inhibition of Mild Steel in Acidic Medium: An Experimental and Computational Study, J. BioTribo-Corrosion, 2019, 5, 1-11. doi: 10.1007/s40735-019-0243-7

40. D.M. Jamil, A.K. Al-Okbi, M.M. Hanon, K.S. Rida, A.F. Alkaim, A.A. Al-Amiery, A. Kadhim and A.A.H. Kadhum, Carbethoxythiazole corrosion inhibitor: As an experimentally model and DFT theory, J. Eng. Appl., 2018, 13, 3952-3959. doi: 10.3923/jeasci.2018.3952.3959

41. A.Y. Issa, K.S. Rida, A.Q. Salam and A.A. Al-Amiery, Acetamidocoumarin as a based eco-friendly corrosion inhibitor, Int. J. ChemTech Res., 2016, 9, 39-47. 
42. H.J. Habeeb, H.M. Luaibi, T.A. Abdullah, R.M. Dakhil, A.A.H. Kadhum and A.A.AlAmiery, Case study on thermal impact of novel corrosion inhibitor on mild steel, Case Stud. Therm. Eng., 2018, 12, 64-68. doi: 10.1016/j.csite.2018.03.005

43. T.A. Salman, A.A. Al-Amiery, L.M. Shaker, A.A.H. Kadhum and M.S. Takriff, A study on the inhibition of mild steel corrosion in hydrochloric acid environment by 4-methyl-2-(pyridin-3-yl)thiazole-5-carbohydrazide, Int. J. Corros. Scale Inhib., 2019, 8, no. 4, 1035-1059. doi: 10.17675/2305-6894-2019-8-4-14

44. ASTM G77-98, Standard Test Method for Ranking Resistance of Materials to Sliding Wear Using Block-on-Ring Wear Test, 1998.

45. K.F. Khaled, The inhibition of benzimidazole derivatives on corrosion of iron in $1 \mathrm{M} \mathrm{HCl}$ solutions, Electrochim. Acta, 2003, 48, 2493-2503. doi: 10.1016/S0013$\underline{\text { 4686(03)00291-3 }}$

46. C. Verma, M.A. Quraish and A. Singh, 2-Amino-5-Nitro-4,6-diarylcyclohex-1-ene1,3,3-tricarbonitriles as new and effective corrosion inhibitors for mild steel in 1 M HCl: Experimental and theoretical studies, J. Mol. Liq., 2015, 212, 804-812. doi: 10.1016/j.molliq.2015.10.026

47. V.S. Sastri, Green corrosion inhibitors: theory and practice, John Wiley \& Sons Ltd, 2011.

48. S. El Issami, L. Bazzi, M. Mihit, B. Hammouti, S. Kertit, E.A. Addi and R. Salghi, Triazolic compounds as corrosion inhibitors for copper in hydrochloric acid, Pigm. Resin Technol., 2007, 36, 161-168. doi: 10.1108/03699420710749027

49. A. Fiala, A. Chibani, A. Darchen, A. Boulkamh and K. Djebbar, Investigations of the inhibition of copper corrosion in nitric acid solutions by ketene dithioacetal derivatives, Appl. Surf. Sci., 2007, 253, 9347-9356. doi: 10.1016/j.apsusc.2007.05.066

50. T.A. Salman, Q.A. Jawad, M.A.M. Hussain, A.A. Al-Amiery, L. Mohamed, A.A.H. Kadhum and M.S. Takriff, Novel ecofriendly corrosion inhibition of mild steel in strong acid environment: Adsorption studies and thermal effects, Int. J. Corros. Scale Inhib., 2019, 8, no. 4, 1123-1137. doi: 10.17675/2305-6894-2019-8-4-19

51. S.S. Al-Taweel, K.W.S. Al-Janabi, H.M. Luaibi, A.A. Al-Amiery and T.S. Gaaz, Evaluation and characterization of the symbiotic effect of benzylidene derivative with titanium dioxide nanoparticles on the inhibition of the chemical corrosion of mild steel, Int. J. Corros. Scale Inhib., 2019, 8, no. 4, 1149-1169. doi: 10.17675/2305-68942019-8-4-21

52. S. Hadisaputra, A.A. Purwoko, F. Wajdi, I. Sumarlan and S. Hamdiani, Theoretical study of the substituent effect on corrosion inhibition performance of benzimidazole and its derivatives, Int. J. Corros. Scale Inhib., 2019, 8, no. 3, 673-688. doi: $\underline{10.17675 / 2305-6894-2019-8-3-15}$ 
53. A. Zouitini, Y.K. Rodi, Y. Ouzidan, F.O. Chahdi, M. Mokhtari, I. Abdel-Rahman, E.M. Essassi, A. Aouniti, B. Hammouti and H. Elmsellem, Corrosion inhibition studies of new synthesized 1,4-dioctyl-6-methyl-1,4-dihydroquinoxaline-2,3-dione on mild steel in $1.0 \mathrm{M} \mathrm{HCl}$ solution using gravimetric and electrochemical techniques supported by theoretical DFT calculation, Int. J. Corros. Scale Inhib., 2019, 8, no. 2, 225-240. doi: 10.17675/2305-6894-2019-8-2-5

54. H. Ashassi-Sorkhabi, B. Shaabani and D. Seifzadeh. Effect of some pyrimidinic Shciff bases on the corrosion of mild steel in hydrochloric acid solution, Electrochim. Acta, 2005, 50, 3446-3452. doi: 10.1016/j.electacta.2004.12.019

55. T. Laabaissi, F. Benhiba, Z. Rouifi, M. Missioui, K. Ourrak, H. Oudda, Y. Ramli, I. Warad, M. Allali and A. Zarrouk, New quinoxaline derivative as a green corrosion inhibitor for mild steel in mild acidic medium: Electrochemical and theoretical studies, Int. J. Corros. Scale Inhib., 2019, 8, no. 2, 241-256. doi: 10.17675/2305-6894-2019-8$\underline{2-6}$

56. N. Khalil, Quantum chemical approach of corrosion inhibition, Electrochim. Acta, 2003, 48, 2635. doi: 10.1016/S0013-4686(03)00307-4

57. M. Filali, E.M. El Hadrami， A. Ben-tama， B. Hafez， I. Abdel-Rahman, A. Harrach, H. Elmsellem, B. Hammouti, M. Mokhtari, S.E. Stiriba and M. Julve, 3,6-Di(pyridin-2yl) pyridazine derivatives as original and new corrosion inhibitors in support of mild steel: Experimental studies and DFT investigational, Int. J. Corros. Scale Inhib., 2019, 8, no. 1, 93-109. doi: 10.17675/2305-6894-2019-8-1-9

58. T. Arslan, F. Kandemirli, E.E. Ebenso, I. Love and H. Alemu, Quantum chemical studies on the corrosion inhibition of some sulphonamides on mild steel in acidic medium, Corros. Sci., 2009, 51, 35-37. doi: 10.1016/j.corsci.2008.10.016

59. R. Javaherdashti, How Corrosion Affects Industry and Life, Anti-Corros. Methods Mater., 2000, 47, no. 1, 30-34. doi: 10.1108/00035590010310003

60. M.M. Antonijevic and M.B. Petrovic, Copper Corrosion Inhibitors. A review, Int. J. Electrochem. Sci., 2008, 3, 1-28. 